\title{
An Unusual Cardiac Mass Associated with Severe Tricuspid Valve Regurgitation: Bloodcyst
}

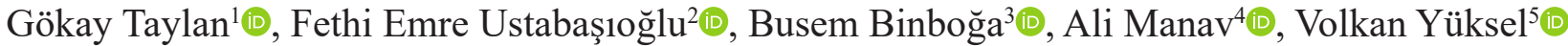

\author{
${ }^{1}$ Department of Cardiology, Trakya University School of Medicine, Edirne, Turkey \\ ${ }^{2}$ Department of Radiology, Trakya University School of Medicine, Edirne, Turkey \\ ${ }^{3}$ Department of Pathology, Trakya University School of Medicine, Edirne, Turkey \\ ${ }^{4}$ Clinic of Cardiology, Luleburgaz State Hospital, Kırklareli, Turkey \\ ${ }^{5}$ Department of Cardiovascular Surgery, Trakya University School of Medicine, Edirne, Turkey
}

\section{To the Editor,}

Cardiac masses are uncommon and can be difficult for clinicians to diagnose. ${ }^{1}$ Blood cysts (BCs) have been considered as rare benign cardiac tumors mostly associated with the enlargement of blood and lymphatic vessels in the valvular structures. ${ }^{2}$ Histopathologically, they are characterized by blood-filled spaces covered by thin layers of flattened endothelium and fibrous tissue. ${ }^{3}$ Even though these valvular masses are mostly asymptomatic, they occasionally reach considerable sizes in adults and induce a variety of symptoms mostly attributable to the dysfunction of the involved valve, transvalvular obstruction, as well as systemic or pulmonary embolism. ${ }^{4}$ In the current literature, these cystic structures have been removed surgically primarily due to obstructive symptoms or valvular dysfunction. ${ }^{3}$ In this letter, we report an unusual case of heart failure associated with $\mathrm{BC}$ of the tricuspid valve in a 74-year-old female patient. Written informed consent was obtained from the patient.

Transthoracic echocardiography (TTE) revealed normal left ventricular systolic functions and massive dilatation of the right cardiac chambers, with a systolic pulmonary artery pressure of $60 \mathrm{mmHg}$ along with a cystic mass involving the tricuspid valve leading to severe valvular regurgitation. Of note, the cyst appeared as a hypoechogenic, thin-walled structure with partial calcification, and seemingly originated from the junction of the right ventricular base and anterior tricuspid valve (video images). Cardiac magnetic resonance imaging (MRI) also confirmed the mobile, cystic, large mass prolapsing through the valvular orifice (Figure 1). Due to progressive symptomatology unresponsive to optimal medical therapy, surgical excision was performed along with repair of the tricuspid valve (Figure 1). Pathological examination was found to be consistent with a BC (Figure 2). The patient was discharged under optimal medical treatment following the resolution of her congestive symptoms.

To date, BCs have been mostly reported in post-mortem specimens of infant hearts. ${ }^{4}$ These cystic malformations generally regress within the early months of life potentially rendering them extremely rare entities during adulthood. ${ }^{4}$ Importantly, the possibility of an existing BC should particularly be considered when a cystic mass originating from the tricuspid valve is detected on imaging modalities. Several hypotheses have been propounded regarding the mechanisms of $\mathrm{BC}$ evolution including vascular dilatation, blood entrapment with consequent seal-off during valvular development, hematoma formation due to vascular occlusion, etc. ${ }^{4}$ Interestingly, BCs were also suggested to represent some sort of cardiac angiomas. ${ }^{4}$

Diagnostically, TTE can be harnessed as a first-line imaging modality. On TTE, a thin-walled echolucent cystic mass might be easily distinguished from a solid tumor. In other terms, detection of a cystic hypoechoic or echolucent valvular mass on TTE should primarily suggest an existing BC. Contrast-enhanced cardiac MRI might further aid in the evaluation of vascularity and degree of fibrosis. ${ }^{5}$ Therefore, MRI might be regarded as a second-line diagnostic strategy that might particularly substantiate the benign nature of a cystic mass. However, histopathological examination appears to be the final decision-making strategy in this setting.

Management strategies in the setting of BCs have been quite controversial. Owing to the lack of general consensus, the decision of surgical excision has been mostly based on the presence of intractable or life-threatening symptomatology as well as patient eligibility for surgical operation. In previous reports, complete excision of the cystic structure has been highly recommended to reach a definitive diagnosis. ${ }^{6}$ However, a conservative strategy has also been

Address for Correspondence: Gökay Taylan, Department of Cardiology, Trakya University School of Medicine, Edirne, Turkey

e-mail: taylan1091@hotmail.com

Received: December 16, 2020 Accepted: January 29, $2021 \cdot$ DOI: 10.5152/balkanmedj.2021.20107

Available at www.balkanmedicaljournal.org

ORCID iDs of the authors: G.T. 0000-0002-7015-4537; F.E.U. 0000-0002-0340-4487; B.B. 0000-0002-7161-1496; A.M. 0000-0003-1071-2872; V.Y. 0000-0001-9518-2588.

Cite this article as:

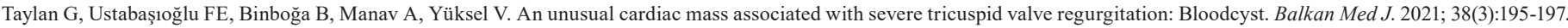

Copyright@Author(s)-Available online at http://balkanmedicaljournal.org/ 

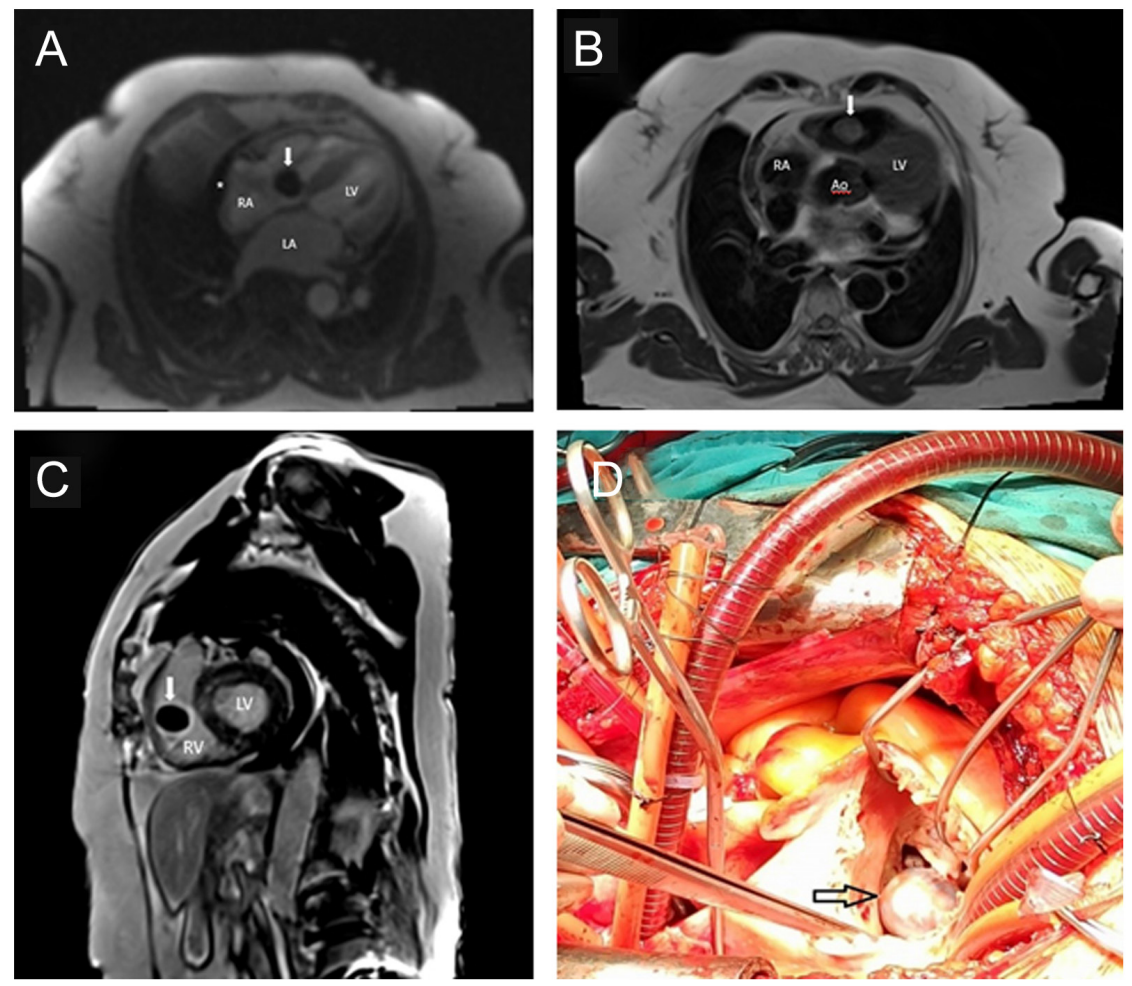

FIG. 1. (A-D). Cardiac magnetic resonance imaging (MRI) images of tricuspid cusp mass. A. Dynamic perfusion four chamber image showing no enhancement within the mass (white arrow), B. Cardiac magnetic resonance imaging demonstrates a mass (white arrow) in the right ventricle which was iso-intense compared to myocardium in axial, T2 -weighted, non-fat-suppressed, black blood image, C. Late gadolinium-enhancement sequence showing no enhancement within the mass (white arrow), D. Intraoperative images of the mass (black arrow). Aorta (Ao), right atrium (RA), left atrium (LA), left ventricule (LV), right ventricule (RV) and mild pericardial effusion $(*)$.
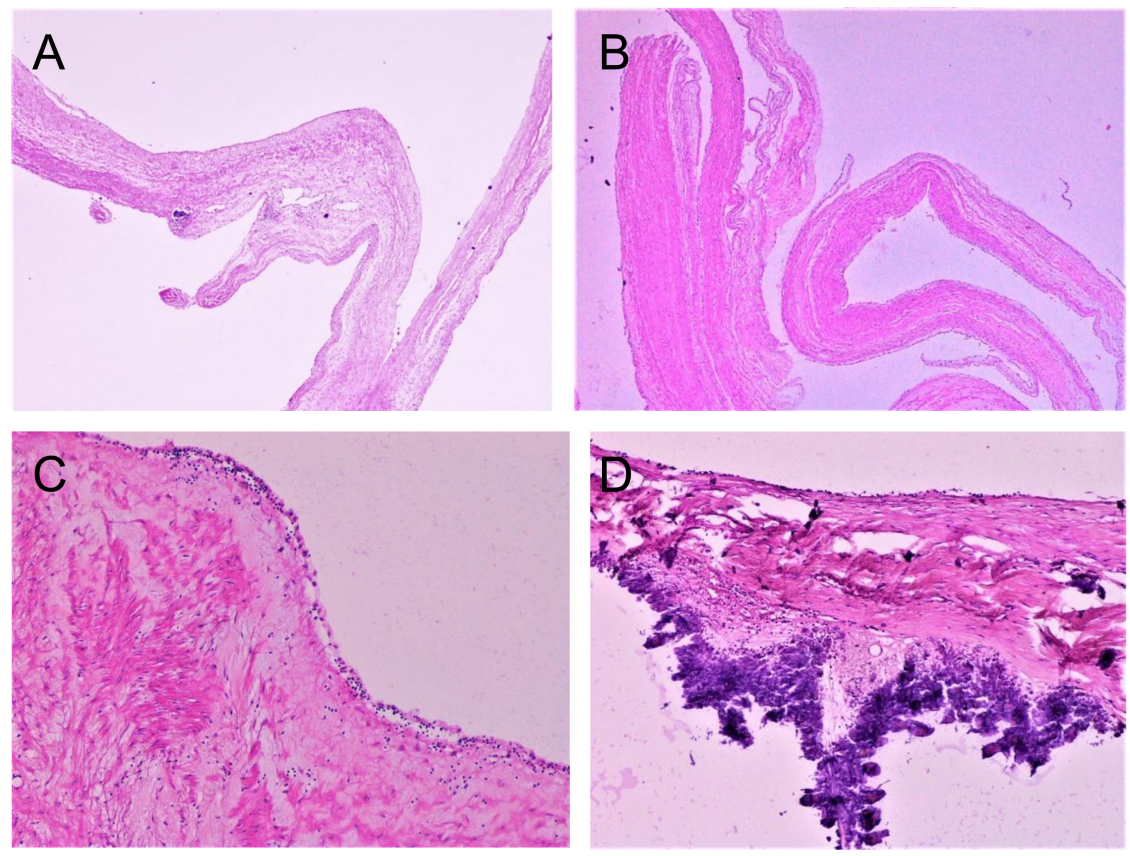

FIG. 2. (A-D). Pathologycal images of trikuspid cusp mass (A and B; Fibrotic cyst wall showing a thin, cobblestone-like endothelium of the surgically excised blood cyst, (HEx40) C; Fibrosis and minimal mononuclear inflammatory infiltration in the cyst wall (HEx100), D; Focal dystrophic calcification in the cyst wall (HEx100) 
suggested as a viable option in recent reports. ${ }^{7}$ We also strongly recommend surgical excision for those with persistent symptomatology and/or signs of severe valvular insufficiency (with or without obstructive signs) on cardiac imaging (as in the present case).

Patient Consent for Publication: Written informed consent was obtained from the patient.

Author Contributions: Concept - G.T., A.M.; Design - G.T., F.E.U., A.M.; Supervision G.T., V.Y., F.E.U.; Resources - G.T., F.E.U., B.B., A.M., V.Y.; Materials - V.Y. B.B.; Data Collection and/or Processing - G.T., F.E.U., V.Y.; Analysis and/or Interpretation - G.T., F.E.U., V.Y.; Literature Review - G.T., B.B., A.M.; Writing - G.T., F.E.U., A.M., B.B.; Critical Review - G.T., F.E.U., V.Y.

Conflict of Interest: The authors have no conflicts of interest to declare.

Funding: The authors declared that this study has received no financial support.

\section{REFERENCES}

1. Kate Y, Syed MP, Doshi A, Patil S, Kumar D. Atrial mass versus thrombus. Balk Med J. 2020;37(3):166-167. [CrossRef]

2. Vuckovic N, Pilija V, Vuckovic D, Capo I. Neonatalmultiplebloodcysts of heartvalves. Cardiovasc Pathol. 2016;25(2):101-102. [CrossRef]

3. Kalçık M, Yesin M, Gürsoy MO, et al. An unusualmass of tricuspidvalve in an adultpatient: bloodfilledcyst. Echocardiography. 2015;32(7):1199-1202. [CrossRef]

4. Park MH, Jung SY, Youn HJ, et al. Blood cyst of subvalvular apparatus of the mitral valve in an adult. J Cardiovasc Ultrasound. 2012;20(3):146-149. [CrossRef]

5. Writing Committee Members, Hundley WG, Bluemke DA, et al. ACCF/ACR/AHA NASCI/SCMR 2010 expert consensus document on cardiovascular magnetic resonance: a report of the American College of Cardiology Foundation Task Force on Expert Consensus Documents. Circulation. 2010:121(22):2462-2508.

6. Paşaoğlu I, Doğan R, Nazli N, Güngen Y, Bozer AY. Blood cyst originating from tricuspid septal leaflet. J Cardiovascsurg. 1991;32(5):589-591.

7. Aydın C, Engin M, Kul S. Tricuspid regurgitation due to blood cyst. Echocardiography. 2019;36(11):2108-2109. [CrossRef] 